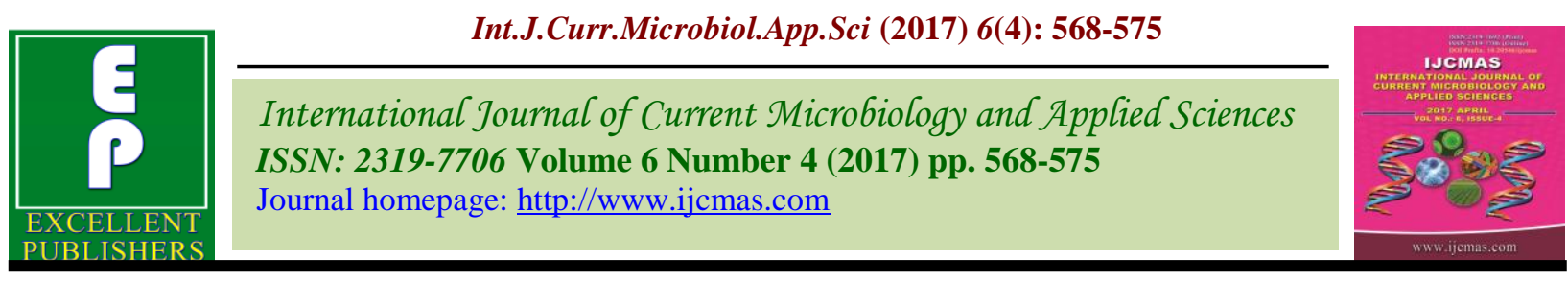

Review Article

https://doi.org/10.20546/ijcmas.2017.604.068

\title{
Fluorescence Imaging for Crop Stress Monitoring: A Review
}

\author{
Brijesh Yadav $^{1^{*}}$, Chiranjeev Kumawat ${ }^{2}$, Anil Kumar Verma ${ }^{2}$, \\ Dinesh Kumar Yadav ${ }^{3}$ and Poonam Yadav ${ }^{4}$ \\ ${ }^{1}$ Division of Agricultural Physics, Indian Agricultural Research Institute, \\ New Delhi-110012, India \\ ${ }^{2}$ Division of Soil Science and Agricultural Chemistry, Indian Agricultural Research Institute, \\ New Delhi - 110012, India \\ ${ }^{3}$ Division of Agricultural Chemicals, Indian Agricultural Research Institute, \\ New Delhi - 110012, India \\ ${ }^{4}$ SKN College of Agriculture, Jobner, Rajasthan -303029, India \\ *Corresponding author
}

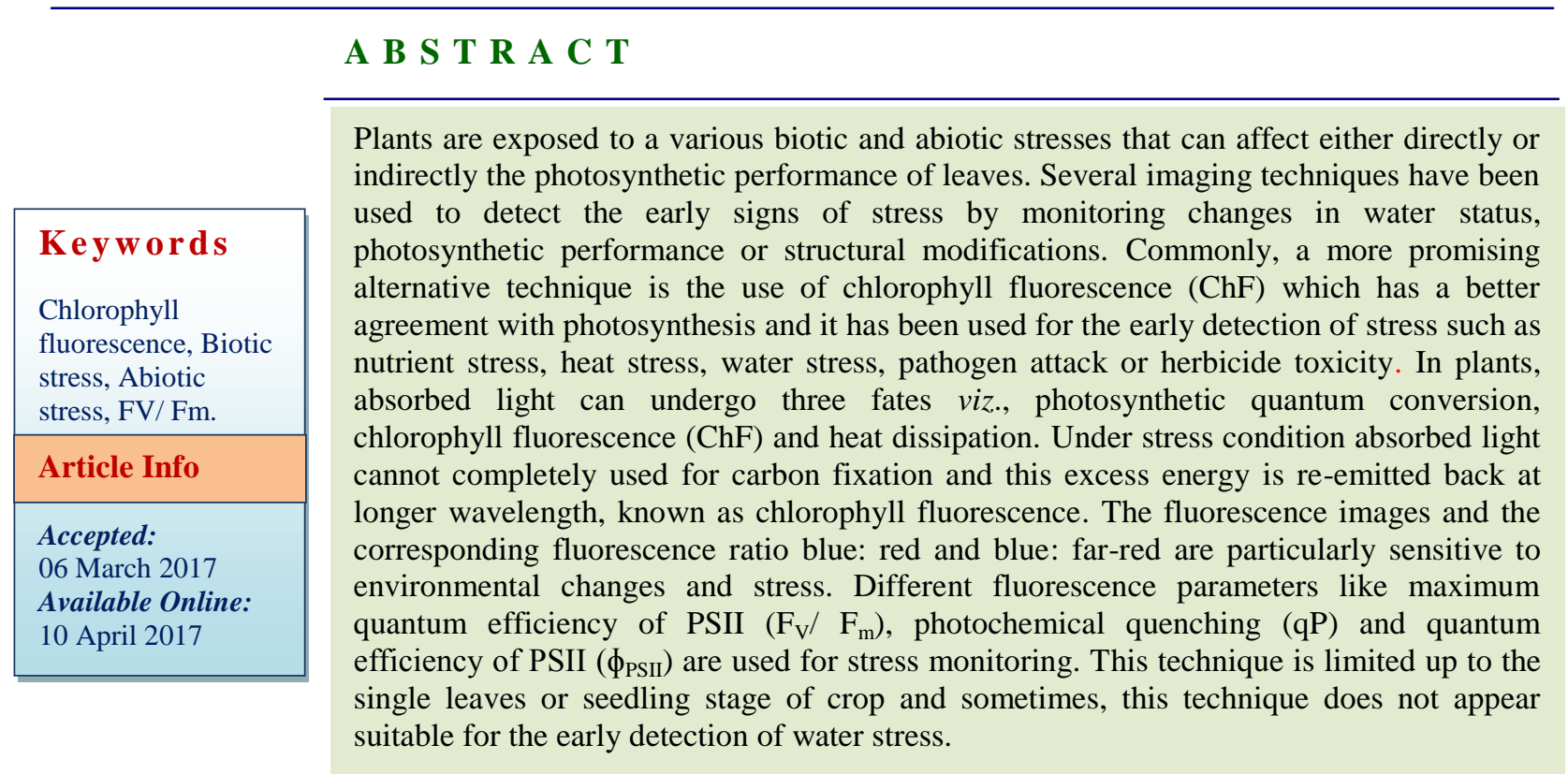

\section{Introduction}

Plants are exposed to a various natural biotic and abiotic stresses. They can affect either directly or indirectly the photosynthetic performance of leaves and modify their optical and fluorescence properties. Stress can be detected prior to any visual symptoms could be observed in crop (Quilliam et al., 2006; Soukupova et al., 2003). Different techniques like thermal, reflectance and fluorescence imaging have been used for detecting stress in crops. These techniques can be applied on microscopic scales (Oxborough and Baker, 1997; Osmond et al., 1999; Küpper et al., 2000; Rolfe and Scholes, 2002), to airborne remote sensing. These imaging techniques can detect the signs of stress by monitoring changes in water status, photosynthetic efficiency, and accumulation of secondary metabolites or structural modifications. But, these techniques do not 
provide reliable measurements and they have little sensitivity to short-term leaf physiological changes. Commonly, a more promising alternative is the use of chlorophyll fluorescence $(\mathrm{ChF})$, which has a better agreement with photosynthesis than spectral reflectance and thermal indices. In the last few years, chlorophyll fluorescence techniques have been widely used as an efficient tool to describe and investigate the photosynthetic performance in plants. Kautsky and Hirsch (1931) have been first time carried out an experiment with chlorophyll (Chl) fluorescence. It is a noninvasive analysis that permits to assess photosynthetic performance in vivo. Chlorophyll fluorescence analysis is widely used to evaluate the photosystem II (PSII) activity, which is an important target of biotic and abiotic stresses. By using these techniques for crop monitoring would allow us to alleviate stress at an early stage and thus substantially reducing yield losses.

\section{Chlorophyll fluorescence}

Solar radiation that absorbed by plant leaf can (i) drive photosynthesis (ii) used as heat dissipation and (iii) can produce fluorescence. These three fates have competition to each other and increase in the one process will leads to reduction in other two processes. In light reaction of photosynthesis, solar energy is absorbed by chlorophyll pigments and it transferred to reaction centers, which ultimately leads to storage of energy. In dark reaction, this energy is consumed for biochemical processes like carbon fixation and sugar production which known as photochemical quenching. During stress condition absorbed light cannot be completely used for carbon fixation and this excess energy is re-emitted back from the leaf at longer wavelength, known as chlorophyll fluorescence or be dissipated as heat (Krause and Weis, 1991; Maxwell and Johnson, 2000). Both processes viz., chlorophyll fluorescence and heat dissipation is called non-photochemical quenching (Fig. 1).

\section{UV induced fluorescence emission spectrum}

Ultraviolet-radiation-induced fluorescence emission spectrum of a green leaf with fluorescence maxima in the blue (F440 nm), green (F520), red (F690) and far-red (F740) spectral regions (Buschmann et al., 2009), blue-green fluorescence is characterized by a high blue fluorescence band ranging from 440 $\mathrm{nm}$ and a lower shoulder in the green wavelength region near $520 \mathrm{~nm}$. Blue-green fluorescence is primarily emitted by two cinnamic acids, p-coumaric acid and ferulic acid (Table 1). Generally poaceae family shows this type of fluorescence. Veins and mid veins of leaf exhibits blue green fluorescence, red and far red type of fluorescence is generated by chlorophyll-a in chloroplast of green leaf (Buschmann and Lichtenthaler, 1998). It has two peaks, 690 $\mathrm{nm}$ and another $740 \mathrm{~nm}$ i.e. red and far-red band respectively. Generally dicots and vein free region of leave exhibit red-far red fluorescence.

\section{Fluorescence emission ratio}

Ratio of fluorescence emission peaks explains the effect of environmental stress on chlorophyll content. Generally four types of ratio are used like- red (F440/F690), blue: farred (F440/F740) and blue: green (F440/F520), and red: far-red (F690/F740). First two ratios are sensitive to changes in fluorescence emission while last one i.e. red: far-red ratio is sensitive to Chl content because of the process of re-absorption of the emitted fluorescence at $690 \mathrm{~nm}$ (Buschmann and Lichtenthaler, 1998; Chaerle and Van Der Straeten, 2000 and Buschmann et al., 2008). But, this is sensitive to $\mathrm{Chl}$ changes only in lightly green leaves $\left(<25 \mu \mathrm{gChl} \mathrm{cm}{ }^{-2}\right)$. An inverse ratio i.e. FRF/RF, varies almost 
linearly with Chl content in the physiological range of crop leaves $\left(20-60 \mu \mathrm{gChlcm}{ }^{-2}\right)$.

Under various stress conditions (high light exposure, enhanced UV radiation, drought and temperature stress) additional UVabsorbing or UV-scattering substances are formed in the epidermal cell, which acts as a barrier to the penetration of UV radiation into the mesophyll cells. The proportion of UV radiation that passes through the epidermis into the leaf mesophyll is strongly reduced and results in a dramatic reduction in chlorophyll fluorescence emission. As a consequence, the fluorescence ratios blue: red (F440: F690) and blue: far-red (F440: F740) strongly increases. The fluorescence images and the corresponding fluorescence ratio images blue: red and blue: far-red are particularly sensitive to environmental changes and stress. The fluorescence ratios are successfully used for detection of different stresses like nitrogen and zinc (on Zea mays) and heat and water stress (on Rhododendron sp.) (Lang et al., 1996). Cadet and Samson (2011) also used fluorescence ratios to determine nitrogen, potassium and phosphorus status in sunflower. Burling et al., (2011) have been used fluorescence ratios to discriminate nitrogen deficiency and disease infection in winter wheat.

\section{Calculation of commonly used fluorescence parameters}

To gain information about the photosynthesis in a plant through chlorophyll fluorescence, it is necessary to discriminate between the photochemical quenching and non photochemical quenching. The typical approach is to 'switch off' one of the two contributors, so that the fluorescence yield can be measured. Figure 2 shows a typical fluorescence pattern when a leaf is exposed to a combination of actinic light, darkness and saturation pulse. When leaf is exposed to light than chlorophyll fluorescence rise up for few seconds due to reduction of electron carriers in the thylakoid membrane, the reaction centre in PSII i.e. P680, eject an electron to the electron acceptor QA via phenophytin. QA is unable to capture another electron from P680 until it passed to next carrier i.e. QB. This state of reaction centre is considered as closed state which leads to decline in quantum efficiency of PSII. After the initial rise of fluorescence, actinic light is applied and results in reduction of fluorescence signal for few minutes which is known as quenching (Krause and Weis, 1991) (Table 2).

When all PSII reaction centers are open i.e. dark adapted state, a modulating light of low intensity is switched on. In this state PSII shows a minimum value of fluorescence, $F_{0}$. The fluorescence emission rises rapidly from a minimal level and attains a maximum $(F \mathrm{~m})$ shortly after the start of illumination. In nonstressed plant or healthy plant, NPQ value is not obtained because material is completely dark adaptive. At this point, maximum fluorescence value is recorded, $\mathrm{F}_{\mathrm{m}}$.

The difference of $F_{0}$ and $F_{m}$ is termed as variable fluorescence, $F_{v}$. The ratio of $F_{v}$ and $F_{m}$ is good indicator of stress in leaves (Krause and Weis, 1991). Subsequently, the signal declines because of quenching, which can be refereed as photochemical (use of light energy for $\mathrm{CO}_{2}$ assimilation) and nonphotochemical (photoprotective) reactions, until a steady-state value $(F$ s or F') is reached. Fluorescence measurements during saturating light pulses are used to enumerate differences in non-photochemical fluorescence quenching.

The application of saturation pulse under actinic illumination condition, close the reaction centre and produce a maximal fluorescence in light adaptive state i.e. F' $\mathrm{m}$. Another widely used parameter is the Photosystem II photochemistry $\left(\Phi_{\mathrm{PSII}}\right)$ for detection of plant stress (Genty et al., 1989). 


\section{Applications of chlorophyll fluorescence imaging for agricultural crops}

This technique has been widely applied for various plant stresses like drought, chilling, freezing, salinity, nutrition, ozone pollution, wounding, high light, high metal accumulation and infection with fungi or virus.

\section{Nutrient stress}

Nitrogen is a part of chlorophyll and play a vital role in photosynthesis so, its deficiency easily can be assessed by this technique. Many studies found that chlorophyll fluorescence imaging is a good indicator for detection of nutrient stress. Application of this technique can help farmers to avoid overuse of fertilizers in precision farming (Chaerle $e t$ al., 2007a). Thus, this technique seems to be useful in site specific nutrient management in sustainable manner.

\section{Water deficit stress}

Water availability is one of the limiting factor for plant productivity especially in arid and semi-arid regions (Flexas et al., 2002). Consequently, a proper monitoring of water stress is necessary for the sustainable irrigation programmes (Penuelas and Filella, 1998). In plants water stress may leads to reduction in photosynthesis. In short term, it is due to either stomata closer or photo inhibition and in long term due to the inactivation of RuBis CO enzyme (Medrano et al., 1997). Hence, Chlorophyll fluorescence can help in early detection of plant water stress and ultimately to irrigation scheduling.

\section{Disease and pathogen}

Many researcher found that chlorophyll fluorescence technique could be used for quantitative screening of disease and pathogen resistance (Barbagallo et al., 2003; Chaerle et al., 2005; Horie et al., 2006).

Table.1 Characteristics of the blue-green and red and far-red chlorophyll fluorescence

\section{Characteristics of the Blue-Green Fluorescence}

\begin{tabular}{|l|l|} 
Fluorescing pigments & Cinnamic acids (p-coumaric acid and ferulic acid) \\
\hline Location and origin & Cell walls and Vacuoles \\
\hline Excitation & UV radiation \\
\hline Maxima & Blue band F440, Green band F520 \\
\hline Exhibit plants & Poaceae family
\end{tabular}

Characteristics of the Red and Far-Red Chlorophyll Fluorescence

\begin{tabular}{|l|l|}
\hline Fluorescing pigments & Chlorophyll a \\
\hline Location and origin & Chloroplasts of green leaf \\
\hline Excitation & UV radiation \\
\hline Maxima & Red band F690, Far-red band F740 \\
\hline Exhibit plants & Dicotyledons \\
\hline
\end{tabular}


Table.2 List of commonly used fluorescence parameters and their formulas

\begin{tabular}{|c|c|c|}
\hline Parameters & Formula & Symbol description \\
\hline \multicolumn{3}{|l|}{ 1. Photochemical quenching (qP) } \\
\hline Quantum efficiency of PSII ( $\Phi_{\text {PSII }}$ ) & $\left(F_{m}^{\prime}-F^{\prime}\right) / F_{m}^{\prime}$ & $\begin{array}{l}\text { Steady state fluorescence }\left(\mathrm{F}^{\prime}=\right. \\
\text { Fs) } \\
\text { Maximal fluorescence in light } \\
\text { adapted state }\left(\mathrm{F}_{\mathrm{m}}^{\prime}\right)\end{array}$ \\
\hline $\begin{array}{l}\text { Maximum quantum efficiency of } \\
\text { PSII }\left(F_{V} / F_{m}\right)\end{array}$ & $\left(F_{m}-F_{0}\right) / F_{m}$ & $\begin{array}{l}\text { Original fluorescence }\left(\mathrm{F}_{0}\right) \text {, } \\
\text { Variable fluorescence }\left(\mathrm{F}_{\mathrm{v}}\right) \text {, } \\
\text { Maximal fluorescence in dark } \\
\text { adapted state }\left(\mathrm{F}_{\mathrm{m}}\right)\end{array}$ \\
\hline Photochemical quenching (qP) & $\left(F^{\prime}{ }_{m}-F^{\prime}\right) /\left(F_{m}^{\prime}-F_{0}^{\prime}\right)$ & $\begin{array}{l}\text { Steady state fluorescence }\left(\mathrm{F}^{\prime}=\right. \\
\text { Fs }) \text {, Maximal fluorescence in } \\
\text { light adapted state }\left(\mathrm{F}^{\prime}{ }_{\mathrm{m}}\right) \text {, } \\
\text { Unrelaxed non-photochemical } \\
\text { quenching }\left(\mathrm{F}_{0}^{\prime}\right)\end{array}$ \\
\hline \multicolumn{3}{|l|}{ 2. Non photochemical quenching $(q \mathrm{~N})$} \\
\hline NPQ & $\left(\mathrm{F}_{\mathrm{m}}-\mathrm{F}_{\mathrm{m}}^{\prime}\right)-1$ & $\begin{array}{l}\text { Maximal fluorescence in dark } \\
\text { adapted state }\left(\mathrm{F}_{\mathrm{m}}\right) \\
\text { Maximal fluorescence in light } \\
\text { adapted state }\left(\mathrm{F}_{\mathrm{m}}^{\prime}\right)\end{array}$ \\
\hline
\end{tabular}

Fig.1 Origin of chlorophyll fluorescence

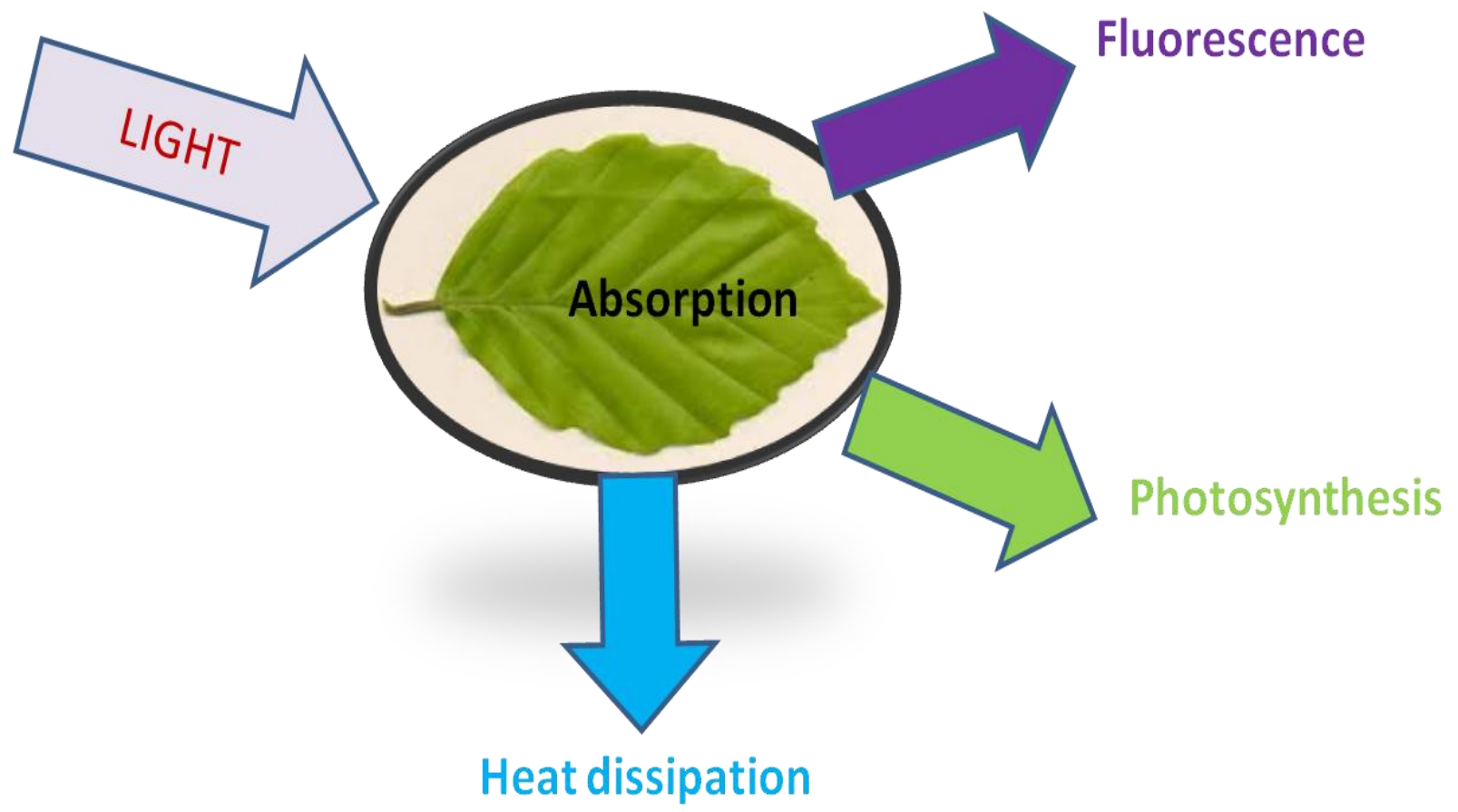


Fig.2 A typical fluorescence trace to measure photochemical and non-photochemical parameters

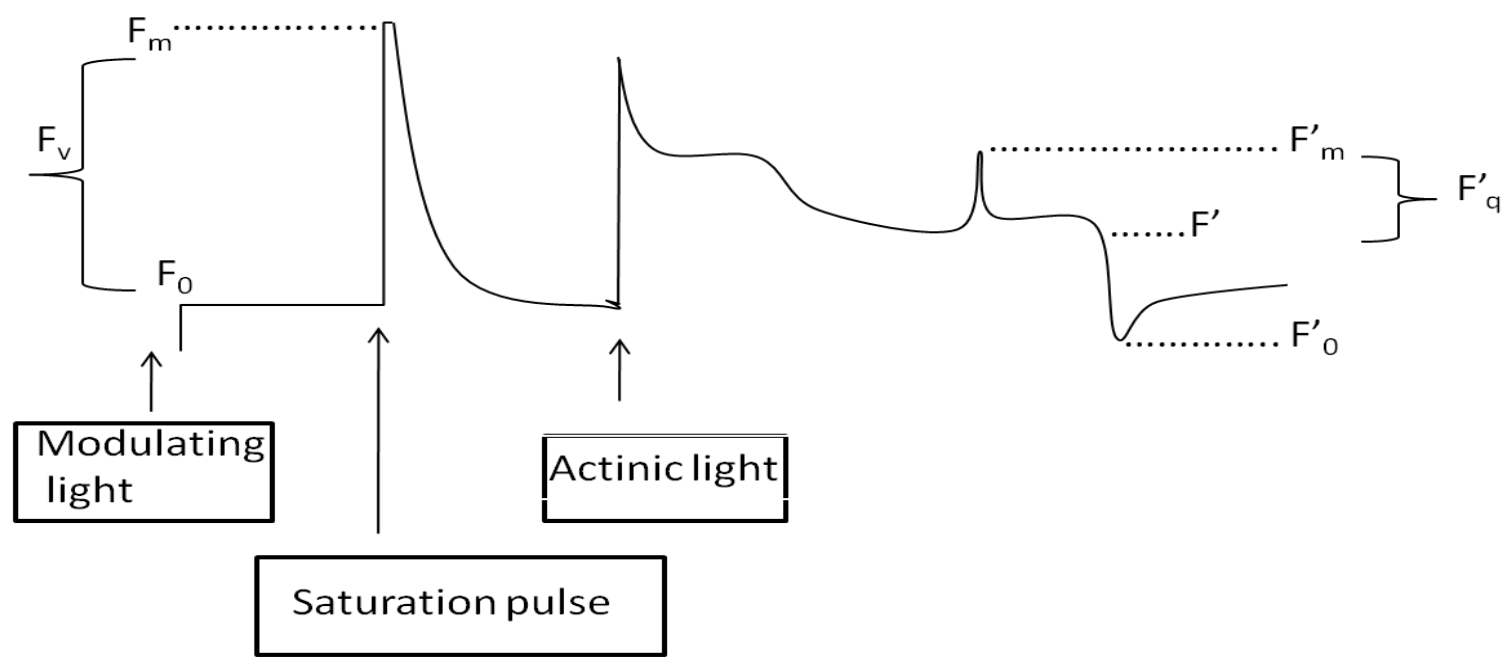

This technique has superior performance for damage evaluation of crop by different biotic stresses.

\section{Elevated temperature stress}

Excess high and cold temperature has adverse effect on plant growth and yield. Under elevated temperature, $\mathrm{CO}_{2}$ assimilation is hampered which results $\mathrm{F}_{0}$ increase and $\mathrm{F}_{\mathrm{v}} / \mathrm{F}_{\mathrm{m}}$ decreases. Cold stress also reduces the values of $\mathrm{F}_{\mathrm{v}} / \mathrm{F}_{\mathrm{m}}$ in the short term.

\section{Excessive sun light intensity and UV exposition}

Although solar radiation is the primary energy source for plant life which determines the crop growth and development but excess radiation is stressful for the plants. To protect the crop from the excessive sun light, farmers use different shade screens depending on the incoming light intensity. UV light is very harmful for crop production due to its interference with biomolecules viz., nucleic acid, lipids and proteins (Tevini, 2004). Thus, early detection of excess and UV light is important factor to achieve a good yield.

\section{Herbicides toxicity}

The application of herbicides alters the plant metabolism which directly or indirectly affects the photosynthesis. This leads to changes in chlorophyll fluorescence emission and it can be detected prior to any visual symptoms appear in crops (Barbagallo et al., 2003).

\section{Limitations of chlorophyll fluorescence imaging}

Most Chlorophyll fluorescence techniques are limited up to the single leaves or seedling stage of crop. Sometimes, the ratio of variable and maximum fluorescence $(\mathrm{Fv} / \mathrm{Fm})$ appears to be relatively insensitive to severe water limitation so, this technique does not appear suitable for the early detection of water stress. Data analysis software is required for fluorescence image processing. Fluctuation in light intensity, during field measurement tends to produce results that entirely different from laboratory analysis. In addition, poor resolution and high power requirements may be limiting for its field applications. 


\section{References}

Barbagallo, R.P., Oxborough, K., Pallett, K.E. and Baker, N.R. 2003. Rapid, noninvasive screening for perturbations of metabolism and plant growth using chlorophyll fluorescence imaging. Plant Physiol., 132(2): 485-493.

Burling, K., M. Hunsche and G. Noga. 2011. Use of blue-green and chlorophyll fluorescence measurements for differentiation between nitrogen deficiency and pathogen infection in winter wheat. J. Plant Physiol., 168: 1641-1648.

Buschmann, C. and Lichtenthaler, H.K. 1998. Principles and characteristics of multicolour fluorescence imaging of plants. J. Plant Physiol., 152(2-3): 297-314.

Buschmann, C., Langsdorf, G. and Lichtenthaler, H.K. 2008. Blue, green, red, and far-red fluorescence signatures of plant tissues, their multicolor fluorescence imaging, and application for agrofood assessment. Optical Monitoring of Fresh and Processed Agri. Crops, 272.

Cadet, É. and Samson, G. 2011. Detection and discrimination of nutrient deficiencies in sunflower by blue-green and chlorophyll-a fluorescence imaging. J. Plant Nutri., 34(14): 2114-2126.

Chaerle, L. and Van Der Straeten, D. 2000. Imaging techniques and the early detection of plant stress. Trends in Plant Sci., 5(11): 495-501.

Chaerle, L., Saibo, N. and Van Der Straeten, D. 2005. Tuning the pores: towards engineering plants for improved water use efficiency. Trends in Biotechnol., 23(6): 308-315.

Flexas, J., Escalona, J.M., Evain, S., Gulías, J., Moya, I., Osmond, C.B. and Medrano, H. 2002. Steady-state chlorophyll fluorescence (Fs) measurements as a tool to follow variations of net $\mathrm{CO} 2$ assimilation and stomatal conductance during water-stress in C3 plants. Physiologia Plantarum, 114(2): 231-240.

Genty, B., Briantais, J.M. and Baker, N.R. 1989. The relationship between the quantum yield of photosynthetic electron transport and quenching of chlorophyll fluorescence. Biochimica et Biophysica Acta (BBA)-General Subjects, 990(1): 87-92.

Horie, T., Matsuura, S., Takai, T., Kuwasaki, K., Ohsumi, A. and Shiraiwa, T. 2006. Genotypic difference in canopy diffusive conductance measured by a new remote-sensing method and its association with the difference in rice yield potential. Plant, Cell And Environ., 29(4): 653-660.

Kautsky, H. and Hirsch, A. 1931. Neue versuche zur kohlensäureassimilation. Natur wissenschaften, 19(48): 964-964.

Krause, G.H. and Weis, E. 1991. Chlorophyll fluorescence and photosynthesis: the basics. Annual Rev. Plant Biol., 42(1): 313-349.

Küpper, H., Šetlík, I., Trtílek, M. and Nedbal, L. 2000. A microscope for twodimensional measurements of in vivo chlorophyll fluorescence kinetics using pulsed measuring radiation, continuous actinic radiation, and saturating flashes. Photosynthetica, 38(4): 553-570.

Chaerle, L., I. Leinonen, H.G. Jones and D. Van Der Straeten. 2007a. Monitoring and screening plant populations with combined thermal and chlorophyll fluorescence imaging. J. Exp. Bot., 58: 773-784.

Lang, M., Lichtenthaler, H.K., Sowinska, M., Heisel, F. and Miehe, J.A. 1996. Fluorescence imaging of water and temperature stress in plant leaves. $J$. Plant Physiol., 148(5): 613-621.

Maxwell, K. and Johnson, G.N. 2000. Chlorophyll fluorescence-a practical 
guide. J. Experimental Bot., 1(345): 659-668.

Medrano, H., Parry, M.A.J., Socias, X.D.W.L. and Lawlor, D.W. 1997. Long term water stress inactivates Rubisco in subterranean clover. Annals of Appl. Biol., 131(3): 491-501.

Osmond, B., Schwartz, O. and Gunning, B. 1999. Photoinhibitory printing on leaves, visualised by chlorophyll fluorescence imaging and confocal microscopy, is due to diminished fluorescence from grana. Functional Plant Biol., 26(7): 717-724.

Oxborough, K. and Baker, N.R. 1997. Resolving chlorophyll a fluorescence images of photosynthetic efficiency into photochemical and non-photochemical components-calculation of $\mathrm{qP}$ and $\mathrm{Fv}$ /Fm-; without measuring Fo. Photosynthesis Res., 54(2): 135-142.

Peñuelas, J. and Filella, I. 1998. Visible and near-infrared reflectance techniques for diagnosing plant physiological status. Trends in Plant Sci., 3(4): 151-156.

Quilliam, R.S., Swarbrick, P.J., Scholes, J.D. and Rolfe, S.A. 2006. Imaging photosynthesis in wounded leaves of Arabidopsis thaliana. J. Experimental Bot., 57(1): 55-69.

Rolfe, S.A. and Scholes, J.D. 2002. Extended depth-of-focus imaging of chlorophyll fluorescence from intact leaves. Photosynthesis Res., 72(1): 107-115.

Soukupová, J., Smatanová, S., Nedbal, L. and Jegorov, A. 2003. Plant response to destruxins visualized by imaging of chlorophyll fluorescence. Physiologia Plantarum, 118(3): 399-405.

Tevini, M. 2004. Plant responses to ultraviolet radiation stress. In Chlorophyll a Fluorescence (pp. 605-621). Springer Netherlands.

\section{How to cite this article:}

Brijesh Yadav, Chiranjeev Kumawat, Anil Kumar Verma, Dinesh Kumar Yadav and Poonam Yadav. 2017. Fluorescence Imaging for Crop Stress Monitoring: A Review. Int.J.Curr.Microbiol.App.Sci. 6(4): 568-575. doi: https://doi.org/10.20546/ijcmas.2017.604.068 